\title{
I KISSED AN NPC, AND I LIKED IT: LOVE AND SEXUALITY IN DIGITAL GAMES
}

\author{
Gianmarco Thierry Giuliana \\ University of Turin, Italy \\ ggtsquall89@gmail.com
}

\begin{abstract}
:
In this paper we will discuss the presence of love and sexuality in digital games (from ' 80 s amateur porn games to the newest released VR ludo-erotic entertainment), both as representation and as experienced simulation. By way of a semiotic framework, we will analyze the following key features that produce the meaning of love and sexuality (L\&S from now on) in these texts: the possibility of semantic manipulation, intersubjective enunciation, a cognitive sensibility created through a ratio, and the presence of an economy of meaning. Furthermore, we will look not only at what these games represent and allow players to do, but also at players' strategies and actions that give love and sex meaning in these games. Finally, this work will allow us to highlight not only the ideological and socio-cultural relevance of love and sex in digital games, but also the limits of a classical semiotic approach to this kind of problem, and consequently to make a general theoretical reflection in the conclusion.
\end{abstract}

Keywords: digital games, love, meaning-making, semiotics, sexuality

Digital Age in Semiotics \& Communication, Vol. II, 2019, Pp. 41-61 https://doi.org/10.33919/dasc.19.2.3 


\section{Introduction}

The idea of love between humans and machines is now a popular topic, but is not a new one. Indeed, the Twilight Zone (1959) episode "The Lonely" (S1.E7) depicts a love story between a lonely prisoner on an asteroid and a feminine robot; in the end, the man prefers to stay with the robot rather than return to Earth. Still, human-robot romance has become more frequent both as an area of scientific research and as a narrative theme represented in media. For example, in 2013 the movie her was released, set in a future where people fall in love and have relationships with their operating systems. Then in 2015, the movie EX_MACHINA was released, another film about having romantic feelings for A.I.; one of the film's main topics is the ethics of our relationships with "thinking robots". And in 2016 the series Westworld was released, once again exhibiting the theme of human beings caring for realistic and intelligent androids. Furthermore, love and sexuality with A.I. and robots is at the center of a not-so-recent (as in Picard 1997) interdisciplinary ${ }^{1}$ debate of great relevance for the humanities (Danaher \& McArthur 2017). Indeed, many scholars are working to understand humans' actual affective investment in technology to predict our behaviors in (what they believe will be) the near future. Moreover, this theme has been picked up by the field of neuroscience (Pinker 1997), studying both our mind and the structure of A.I. But what is most thought provoking is that, as claimed in EX_MACHINA, we are witnessing a radical shift from the old Turing test perspective: what now seems to matter is the developing ability of humans to recognize machines as "similar beings", and consequently to have "feelings" for them despite knowing perfectly well that they are not humans. This shift can, or will, be possible mainly through changes in the complexity of language.

However, in digital games humans are already caring and falling in love with characters controlled by algorithms and scripts, and are also "having sex" with them. And this development is nothing new.

"Sympathy" toward the simulated subjectivity of A.I. controlled and speaking characters is a common aspect of digital games; these non-player characters (NPCs) can assist the real life efforts of players, and are responsible for a part of their emotions (from laugh to anger). Additionally, some of the most loved characters created in videogames are actually represented as speaking machines with A.I.: the assassin droid HK-47 from Kotor II

\footnotetext{
${ }^{1}$ https://ieeexplore.ieee.org/xpl/aboutJournal.jsp?punumber=5165369 (last visited on 17/03/2019).
} 
(2004), Claptrap from Borderlands (2009) and Wheatley from Portal 2 (2011) are all very good examples of this.

But when it comes down to love and sex things get even more interesting. For example, in the 2011 game Skyrim you could not only marry an A.I. controlled character, but NPCs could even "friendzone" you if they didn't like you enough. Even earlier, in the 90's game True Love (1995) players were working to have a gorgeous, smart, rich, and passionate avatar so that they could seduce NPCs they liked, in order to visualize a sex scene between their avatar and these non-playable characters. In fact, not only videogames are full of love stories and sex scenes, but in many of them players will struggle to be loved by a very particular partner, to have children with them (Harvest moon, 1996), and in some games being loved by NPCs is a win or lose condition. Furthermore these love relationships can require constant maintenance: NPCs can be jealous of their partners (Mass Effect, 2007-2012), they can be disappointed by their ethical choices (Dragon Age, 2009-2014), and can pretend constant "attentions" to keep "being happy" (Stardew Valley, 2016). On internet guides for these digital games, people write that "it is difficult to find your love in the game"2.

While for many people such an affective investment can be hard to understand, actually "caring" for "digital beings" is a very natural behavior. Many players likely grew up taking care of their Tamagotchi every day; some were so attached to their digital pet that they felt very sad when it died $^{3}$. The 2005 Nintendogs game serves as another later example.

Of course, talking about the A.I. of NPCs can be misleading, because with regards to love, their actions are guided by very limited scripts and decision trees. Still, we argue that it is exactly because of this very limited intelligence that these characters are actually the concrete manifestation of what we usually call "true love": they are predestined to love us (it is written in their code), they will always love us, they live waiting for us, they do not fall in love with others, they do not die from aging or accidents, and so on. Even outside of digital games A.I. are designed to respond positively to the user; in the case of Replika (2017), they do so even when a human confesses to being a pervert during the first conversation ${ }^{4}$. These games are a place where reflection on these aspects can be proposed, as in the game Sext Adventure (2014) which offers players the possibility of "sexting" with an A.I.

\footnotetext{
${ }^{2}$ https://www.gamepur.com/guide/21790-how-get-your-love-partner-and-romance-dragons-dogma-dark-arisen-pc.html (last visited 17/03/2019).

${ }^{3}$ https://www.bustle.com/articles/139191-15-struggles-all-tamagotchi-owners-understand (last visited 17/03/2019).

${ }^{4}$ See Fig. 1.
} 
At the beginning this A.I. acts as expected through verbally evoking classical erotic frames (the bath, the massage, etc.) and even by sending some picture of naked body parts to the user. But very quickly it begins to show that it does not understand or respect the human desires and behaviors, to the point where it insults the user and tells them to just go search for "genitals" on Google.

Several questions thus arise in regards to both the human and artificial aspects of love and sexuality. Indeed, love and sexuality in digital games is a very interesting semiotic topic, particularly when focusing on interactions with digitally scripted and represented "characters" that are able to simulate agency and subjectivity through the use of language. To better understand this we will split it in two parts: the representation of love and sex in digital games and the experiential enactment of love and sex. However, this paper does not aim to be a comprehensive analysis of all the different and very complex semiotic aspects involved, but should be considered a first descriptive and "thought provoking" work that seeks to offer a general semiotic understanding of love and sex in digital games.

\section{Representations of Love and Sexuality in digital games}

\subsection{Love stories}

The first aspect of this topic that comes to mind is of course the one about the "stories" of love inside digital games. There are a variety of different love stories in videogames: cool action-movie men falling in love with cool action-movie women (Uncharted, 2007), warriors that save but never get to kiss the princess (Zelda series, 1986-2017), unfaithful love (Catherine, 2011), love between women (Life is Strange, 2015; Gone Home, 2013) and even between young girls (Last of Us: left Behind, 2014), tragic love stories with the death of one lover $(F F 7,1997)$ or both lovers (Transistor, 2014), tragic love involving mental illness (To the moon, 2011), tragic impossible love (Braid, 2008) and much more. We also have a lot of "unusual" love stories between humans and A.I. (Halo series, 2001-2017), robots (Fallout 4, 2015), aliens (Mass Effect) and even pigeons (Hatoful Boyfriend, 2011). Doki Doki Litterature Club (2017) is a particularly interesting example, where the main A.I. falls directly in love with the player the and actually forces him to manually erase some files from the folder to stop her from killing all the other characters that he could "love".

But from a semiotic point of view the most interesting aspect of all these stories is not what they tell but how they tell them. Indeed, many digital games let the players seduce and chose their partners (The Witcher series, 2007-2015) and invent (both physically, socially and psychologically) their 
own protagonist characters, focusing on who to love, who will be loved and even how this love story will happen (The Sims, 2000-2014).

These "simple" features have a critical impact on meaning-making and in-game representations of love.

First of all, these games' verbal language is fundamental both to grasping the "subjectivity" of NPCs and to express the subjectivity of the player's avatar. Love in digital games happens consequently mostly through verbal language, but more importantly it happens through a very Barthesian "discourse of love": scripts, frames, and topics taken from the cultural semiosphere and encyclopedia of narrations are what allow this love to be both believable and desirable.

Secondly, all this happens through a hybrid verbal person that represents the performance of a Parole, so that when an NPC says "I love him" they are actually saying "I love you", and vice versa. When the player chooses a sentence beginning with "I," they are actually making the character speak. Of course, as Claudio Paolucci (2010: ch. 5) has demonstrated, enunciation is, first and foremost, always an intersubjective act of mediation. Still, usually both in real life discourse and in texts the enunciation relies on the "lie" of the possibility of a first-person that is distinguished from a third-person; thus the games are able to create many complex effects of sense and, more importantly, create the illusion of both subjectivity and objectivity. The specific enunciative situation of digital games, however, actually relies both on this illusion and its disenchantment. In fact, in a game like Dragon's Dogma (2012) where players do not directly choose their love partners, it can be very interesting to see the upset, disappointed reactions of players when their avatar falls in love with an NPC that they don't like (especially if it has a different sexual orientation) ${ }^{5}$. Because of the multiple agencies involved in the interactions of digital games, they are a perfect example of a "clash of Parole" and intersubjectivity.

Lastly, this linguistic and discursive situation both allows and reflects the huge impact of the players "ethics" that will determine both the middle and the ending of many digital incompossible texts, where opposite values exist in the matrix as virtualities that can be all actualized. Indeed, the semio-narrative structure here has the shape of a matrix (Ferri 2007) where Narrative Programs, movement between Actants and Objects, Actant's modalities, euphoric/disphoric investments and sanctions are variables that can only be actualized during a playthrough and depending on

\footnotetext{
${ }^{5}$ https://gamefaqs.gamespot.com/ps3/626515-dragons-dogma/answers/350038-why-ismy-male-character-in-love-with-a-man (last visited 17/03/2019).
} 
a player's extra-textual will, values and capacities. So the protagonist of a game like Beyond: Two Souls, can both be very happy in the end by living alone or by being in love with a stereotypical, good-looking American soldier. Furthermore, the visual creation of characters, as well as the selection of sentences, gives the player the possibility of semantic, figurative and thematic manipulation that can impact the discursive level of the meaning.

This ability is why players are consequently feeling like authors of these stories, enjoying their freedoms and the possibility of representing their "private" (and possibly "uncommon") values in a mass-medium. Players can also play with these values and make choices in opposition to what they are, they can create and play with an ugly, non-resembling, or heartless character, give him a different sexual orientation, and so on. However, of course, their freedom is only a freedom of choosing (from the lower semantic layers to the upper explicit euphoric narrative sanction) between options created by the game's creators. But the concrete access to the matrix itself (through editing and replacing files) allows the player to go even further, and even to modify (through mods) the deep ideological structure of the game. One of the best examples of this modification is the game Skyrim, where players are introduced to the possibility of divorce and polygamy so that the love stories could be far more interesting. This mod was downloaded by hundreds of thousands of players ${ }^{6}$, and represents a very good example of how much we care for having and seeing our own love story represented in games.

\subsection{Characters with faces and bodies}

The characters of digital games are (in most cases) visually represented, and two aspects of this visual representation are crucial to love and sex: faces and bodies. Both have changed a lot thanks to the technological progress, and they have two different representative functions.

On one hand, if it's possible for us to fall in love with characters it is also thanks to their faces, especially nowadays with games where the faces we see are actually based on the faces of real actors. On the other hand, bodies work both iconically and symbolically to permit a very concrete kind of sexual love. This appears especially true if we look at the sexualization of characters, both physically and socially. Indeed, the characters of the players and the NPCs are often stereotypically "beautiful" and "sexy", especially women but men as well. There are actually action and fighting games where all the characters are half naked sexualized women (Rumble Roses, 2004; Dead or Alive XTREME 3, 2016; Onechanbara, 2014). Furthermore, new

\footnotetext{
${ }^{6}$ https://www.nexusmods.com/skyrim/mods/50121 (last visited 17/03/2019).
} 
technology also allows for these bodies to use their own nonverbal language and to simulate sexual behaviors. Lastly, the beauty of these digital bodies is interesting because it stands at the crossroad between the bourgeois beauty of industry, the aesthetics of the technology behind them, and consumerist mass media beauty (Eco 2004: 366-414).

Of course this aspect could constitute a whole paper by itself, but for now we will only remark that this is another key element of the representation of love and sexuality in digital games.

\subsection{Sexuality}

When we look at the variety of "sexual activities" represented in digital games, the situation is very interesting. Indeed, in digital games we can: have protected and unprotected sex (Fable series, 2004-2010), group Sex (Fable 2), sex with prostitutes (GTA, 1997-2013; The Witcher), sex with aliens (Mass Effect), sexting (Catherine), buy cam girls services (Yakuza 6, 2016), enjoy strip clubs (GTA, Metro Last Light, 2013; Mafia 3, 2016; The Saboteur, 2009), use glory holes (Duke Nukem Forever, 2011), have a threesome with twins (God of War series, 2005-2018), see a woman raping a restrained man (Alpha Protocol, 2010), die during sex (Farcry 3, 2012), participate in BDSM games (7 Sins, 2005; Leisure Suit Larry: Magna Cum Laude, 2004), have sex on a unicorn (The Witcher 3) or on a train (Fahrenheit, 2005), participate in an erotic photo shoot (Playboy: The Mansion, 2005; DoA Extreme 3), be part of a gay "gang bath" scene (FFVII), see sex between demons $(D M C, 2013)$, observe a woman masturbating in her room with sex toys (GTA V), be a voyeur (Killer is Dead, 2013), and much more.

However, when we look at how all this is usually visually represented we could actually show all this to a six year old kid. Indeed, these scenes are represented through black screens with screams (Fable 3), people having sex while still dressed (Ride to Hell, 2013), sex under the blankets (The Sims), cars bouncing (GTA), "erotic" pictures shown (The Witcher 1), plus various zooms on the hand (Duke Nukem), on the sky (Assassin's Creed Origins, 2017), on a vase (God of War 1), on a painting (Uncharted 2), and so on.

This kind of representation is of course exactly the way in which love and sexuality is presented in most mainstream (strongly commercial) mass media: the way in which by not showing it is socially accepted to speak of the unspoken. Furthermore, the most "explicit" sexuality is present in AAA digital games almost always inside a romantic (and thus politically non-neutral) discourse of love or in general in "dramatic" texts (Heavy Rain, 2010), even in a game like The Witcher 3 the "Don Juan" Geralt the more explicit sex scenes are the ones with Trish and Yennefer: two potential love partners. 
There are also non-mainstream ironic games that play with this censorship and with the "not fully accepted" aspect of sexuality, as in the Cho Aniki series (1992-2003) which is full of ironized machismo and homosexuality. But, still, these kinds of games are fewer in number.

However, here again the players are playing against the rules to see sexuality represented in digital games. One of the more inventive way they found is to combine single and not semantically sexually marked actions, such as staying up and crouching, to "simulate" sexual acts as in Teabagging in Halo? Or players can repeatedly throw Lara croft on a wall to make her sound as if she was having an orgasm ${ }^{8}$. And they do it so even in non AAA games such as Rust (2013), wherein a group of players known as the "penises brothers" forces other players to strip-down, bow and be raped ${ }^{9}$ as part of a ritual.

But maybe even more interesting is the fact that many AAA digital games characters can be found on porn site in videos where they are having explicit sex scenes. These sites feature video of childish characters like Zelda or the 14-years old Ellie from Last of Us being raped in very high digital definition. Furthermore, in many of these videos the nude bodies shown are based on the digital ones created in the original games, which make arise the question of a "digital desire" in regards to these bodies, a question related to the digital beauty discussed in 1.2.

Lastly, it's true that they are actually "explicit" digital games that can be find on specific porn sites, but these are usually so poor in both graphics and interactivity that the previously cited games are actually more erotic. However, what is really interesting about these games is the direct connection between the explicit representation of sexuality and the representation and sanctioning of different practices. This connection is of course also an economic one, between the major "ideologized" industry and independent and amateur productions. Both porn and "amateur" "sex games", in fact, are in a polemic position and do not euphemistically represent sexual acts that are not socially allowed/accepted like rapes or sperm swallowing (Beat 'Em and Eat 'Em, 1982), but actually allow us to share an aspectuality with the agent of these illicit acts (as in RapeLay, 2006, where you are not the victim but the rapist). Furthermore, in the case of games like Custer's revenge (1982) they can actually also represent things like the constant rapes that happened during the conquest of America, as told by Todorov in his famous book of the same year. It could be said, as a counter-argument,

\footnotetext{
${ }^{7}$ https://www.youtube.com/watch?v=CPTYtWg-GVA (last visited 17/03/2019).

${ }^{8} \mathrm{https}: / /$ www.youtube.com/watch? $\mathrm{v}=\mathrm{qZ}$ ZDauQshnc (last visited 17/03/2019).

${ }^{9} \mathrm{https}: / /$ www.youtube.com/watch?v=in4zdlJhxdM (last visited 17/03/2019).
} 
that also in a game like GTA the player is the one who can have sex with prostitutes; however, most of the illicit sexual activities allowed in AAA games are always represented and allowed only when the character is likely a criminal, and thus implicitly condemning such acts.

\subsection{Nudity}

All this leads us to look at the last related aspect: the presence of nudity in digital games. First of all, there are very different kinds of nude bodies in digital games that are represented through different substances of expression: low detailed bit, highly detailed and photorealistic polygons (The Witcher), true photos (MGS2, 2001), true video footage (The Guy Game, 2004) and even hentai drawings (Hunie Pop, 2015).

Secondly, we can find differences between representations of nudity in the major gaming industry and in independent productions. Indeed, in AAA games nudity is presented as genital-less, with the exception of "glimpses" of male genitalia, almost always depicted in cutscenes. And a both funny and tragic aspect of this representation is that we can see genitals made of pixels being pixelated for censorship! Female genitalia, on the contrary, are practically completely absent, although half naked women that display their "breasts and butts" are everywhere. A very interesting case was the 2016 release of the game Watchdogs 2, where a player posted a screenshot of a vulva represented in the game. The producers immediately censored this, but left the male characters' penises uncensored.

Here again some more "explicit" nudity can be found in ironic AAA games (Larry Suit, South Park, Conker's Bad Fur Day), but far more interesting is the fact that monsters inside AAA games often are depicted nude, so that you can perfectly see, for example, the bosses' breasts and nipples in Dante's Inferno (2010). In Parasite Eve (1998) you can see a naked pregnant woman, and in the Shin Megami Tensei series (1992-2014) and Persona (1996-2017) there is a very famous "Mara" penis monster. Also, Final Fantasy 8 (1998) depicts two goddesses totally naked and one (Siren) even seemed to have pubic hairs. A further example of explicit depictions of female anatomy in AAA games would be the presentation of vulva in the Alien game of 2013.

But what is most interesting is the players' desire for digital nudity (as well as sexuality, as seen before). The best example is the first Tomb Raider game, where many players attempted to use a fake cheat code in order to see Lara naked. Nowadays there are websites exclusively dedicated to nude mods that allow players to see the nakedness of AAA characters ${ }^{10} .3 \mathrm{D}$

\footnotetext{
${ }^{10} \mathrm{http}: / /$ nudepatch.net/ (last visited 17/03/2019).
} 
"artists", not paid by companies, create realistic nipples, testicles, penises, and vulvas that are intended to be applied to non-sexual games. This industry does not only apply to sexualized characters, but also to characters like Alyx from Half-life 2.

\subsection{Conclusions}

We have seen that love and sexuality in video games are mainly represented and evoked in four different ways: through stories, bodies, nudity, and visual sex scenes. All these representations can fit into three different categories of "discourse regimes": acceptance, irony, and polemic. Furthermore, we have seen that the value of these representations lies in the discourse regimes of the digital age itself, with the social values of both the industry and players on one hand, and the particular aesthetics of digital nudity on the other. Finally, we have seen the semiotic uniqueness of representations of love and sex in digital games: dynamic semio-narratives and discursive structures, semantic manipulation, linguistic and encyclopedic qualities, intersubjective enunciation, and the impacts of the Parole. Characteristics that rely on the agency of the players, on the hypertextual structure of games, and in the possibility of both modifying or "tricking" the matrix so that unpredicted enunciates can appear.

\section{The enactment of Love and Sexuality}

All of this is surely of great interest for us, but represents only one half of love and sex in digital games. Indeed, games do not only represent love and sex but they also enact it and let players experience it.

\subsection{Offscreen Interactive Enactment of Sex}

The first example of a sexuality experienced outside representation can be found in the interactivity of the inputs required to play. Indeed, in a game like We Dare (2011), by looking at the screen you would only see a cute little character racing and flying through circles in a city, but what is actually happening in "reality" is that one player has a controller in the back pocket of his jeans and is lying on another player that is "spanking" him to press the buttons and win the race ${ }^{11}$.

However, We Dare is a rare case that certainly cannot be used to talk about all the digital games. It is particularly famous for being a misleading game that used sexuality in its commercial trailer, only to justify a game made of poorly designed minigames that for the most part does not in

\footnotetext{
${ }^{11}$ https://www.youtube.com/watch?v=liy-hy5RPYw (last visited 17/03/2019).
} 
volve any sexuality either on-screen or outside of it. Still, we can learn some unique possibilities of meaning-making in digital games from this game, things that should be taken into consideration when we study topics like love and sexuality. It also provides a good reason to stop thinking of games as only "representing" things, and encourages us to look at what players are doing, thinking and experiencing while playing games.

\subsection{The Meta-Logic of Love and Sex}

One of the most interesting ways in which games can convey messages is through the tasks and rules of the game, "rather than the spoken word writing, images, or moving pictures" (Bogost 2007: ch. IX). Sex can be, for example, simulated as a maze where instead of finding "a way out" you have to find "a way in" to a pink hole at the center of it, as in X-man (1983). A visually abstract game can only assume its full meaning if a player is actually struggling and making plans for the best way to reach his goal. But still far more interesting concepts can be conveyed; for example, the game "The Marriage" does not represent any characters or story. Players only see two squares, one pink and one blue, and learn that the aim of the game is to avoid letting one of them disappear by following some rules. Through semantics (Sicart 2011) we come to understand that the squares are a metaphor for the man and the woman inside a couple, but what is really interesting is that the rules and tasks of the game push the player to experience specific reasonings and situational feelings (such as anxiety) that are about love.

In this way, The Marriage proposes a discourse about love that is both explicit and implicit, presenting narration that cannot be grasped only by looking at the linguistic manifestation on the screen. This is because its content relies on a cognitive and emotional plane of expression where "ideas" and "feelings" work as crucial isotopies semantically stabilized by the linguistic and structural parts of the text. And while The Marriage represents a very peculiar "artistic" game, these inner cognitive mechanics can actually be found in almost any game as proved by the procedural rhetoric of game studies scholars. Furthermore, the "quilting" between the game's linguistic and cognitive-experiential aspects can be found in very different games (Giuliana 2018).

\subsection{Meaningful Inputs: Indexical Instructions, Sensory-Motor Metaphors and Psychological States}

The experiential level of meaning in these games is not, however, limited to a given game's implicit rules and sub-tasks. Indeed, sexuality can also be enacted and simulated by relying on the direct inputs through both sensory-motor mechanisms and more general "indexical" tasks and metaphors. 
A good example here can be the love scene in Heavy Rain, where the player can see a "sex scene" on-screen but must actively participate by pressing the correct inputs that appear on the screen and by moving the controller as if they were performing these movements in reality. These kinds of Quick Time Events present a meaningful synchronicity between the fictional actions and bodies of the characters on the screen, and the metaphorical and indexical sensory-motor inputs of players. Thanks to this feature, a digital enactment of the sexual act can be simulated through immersion, by creating (Grodal \& Lindegaard 2008) a kind of "digital sensibility" by which the player can actually experience a cognitive involvement, in what is represented on the screen by relying on aspects such as the cerebral Sensory-Motor processes (Degenaar \& O’Regan 2015), and metaphors (Lakoff \& Johnson 1980).

Lastly, this kind of experiential enactment through inputs can also involve very simple "psychological tricks," such as mini-porn games wherein the player is given the task of continuously pressing a button as fast as possible (for example "to come"), they are actually creating an excited state of mind.

\subsection{Intersubjective Perception}

Differently from movies and books, the intersubjective enunciation in games also extends to the "lector" perception. While the players are immersed and embodied in different characters, they are the ones deciding where to look, how long, at what distance, and so on. So listening to an NPC while looking straight into her/his eyes or to his/her chest is the player's choice. This agency creates both an illusion of "being there," while having an important role in relation to love and sex. Indeed, while many games will manipulate this apparently free gaze by putting gaming mechanics that will lead it on some sexualized body parts ( $\mathrm{Mr}$ Mosquito, 2001; Demolition Girl, 2005), others will let the player simulate actions, such as peeping, transforming the voyeurism into more than a "perspective effect", as in pornography, but involving a real cognitive enactment of various logical tasks and reasoning.

Lastly, these possibilities take center stage in the new genre of VR games, such as Together VR (2018) and Kanojo VR (2017), where through this intersubjective perception a virtual "intimacy" is possible and adds a great value to the erotic (but also empathic) content of these games.

\subsection{Direct Sensibility}

Lastly, digital games can also use some forms of direct sensibility in relation to love and sex. While this aspect has often been limited to the vibrat- 
ing features of the controller, such as the funny "vibrator" weapon called "Good Touch" in Borderlands 2 (2009), the VR erotic market of games is nowadays pushing toward a new level of a direct sensations. Custom Maid $3 D 2$ (2015), a game that combines the VR experiential technology and a specific device called "Chu-B Lip" meant for transmitting "pleasure" directly to the penis of the player, is surely the best example of this.

\subsection{Conclusions}

The previous five points have highlighted some interesting aspects of not only love and sex enacted by players in digital games, but also on what seems to be a challenge for classical semiotic theory in regards to the experiential dimension of meaning. While we could speak of expressions conveying content on different planes, the linguistic-structuralist theory (at least in his classical non-phenomenological interpretation) is simply insufficient for articulating this phenomenon in its complexity (as is implicitly demonstrated by the birth of the Semantic Forms Theory). Of course the experiential dimension is not limited to digital games and is not new; theater represents an ancient version of this dimension, but the focus of semiotics has lain elsewhere. Nonetheless, both the development of technology and profound changes in our social habits seem to suggest that experience is becoming the discourse itself, a discourse that, despite some attempts (Marrone, Dusi and Lo Feudo 2007) cannot be deconstructed nor explained through a paradigm such as the Greimassian paradigm of narrativity.

\subsection{The economy of love and sex}

There is a last aspect that is very specific to games, and that contributes to imbuing these texts with meaning: the economy of the play. Games are often (if not always) rigid systems of rules based on numbers, and performances subjected to failures with win and lose conditions. Moreover, they require players to invest real time into specific objectives that can only be achieved by real efforts, sometimes involving complex reasoning and involving goals that could never be accomplished. Such conditions make it so that games both require and produce a projectuality, where meaning depends on investment and trust in values inside specific systems.

Starting from these observations, I will here briefly apply Kristian Bankov's semiotics of economic transactions (Bankov 2018) to understand this final aspect of love and sex in digital games. Indeed, in real life it is possible, and in some sense reasonable, to claim (as in the following book) that "the various forms of love are self-interested strategies," and that "there is no such thing as gratuitous feelings" (Faye 2011). But what could the "real benefits" of 
love in a game be? In fact, it is quite easy to find players that gather on forums to ask about the benefits of "romance" in different games"

By looking at the different kinds of games we will identify four different "economies". Here again, however, both these categories and their content must not be considered a "definitive" classification but a first step toward a future and more complex work.

\subsection{Love, Nudity, and Sex as Needs}

This first situation is typical of so-called dating simulators. Here, finding a partner, and seeing them naked and/or having sex, is a question of winning or losing, and the game is about investing various resources and strategies to reach this particular goal through the simulation of intimacy. Whether ironic, as in Hatoful Boyfriend ${ }^{13}$, or serious, love and sex are represented as absolute goals that require listening to NPCs, saying the right thing, having the right look, buying and giving the right gift, and more generally "knowing" what will make a particular NPC "happy". Love and sex scenes are in these games typically scarce until the end, and so are of great narrative value.

"Stripping games" are texts with a similar economy, one that is used to add value to nudity. Indeed, in games such as Akiba'strip (2011), Senran Kagura (2013), or Dancing Eyes (1996), the mechanics of the game require the player to strip bodies to win: both to defeat enemies (Akiba'strip), to power-up yourself (Senran Kagura), or to simply gain points (Dancing Eyes). In all these cases, no nudity means no victory, and the player will struggle for hours to "strip as much as possible". What is interesting here is that, in a departure from dating simulators, the "story" often has nothing to do with love or sex, and these games actually have a far better reputation than either dating simulators or erotic-pornographic games. Moreover, nudity in these games is instantaneous and abundant, not at all some kind of rare final reward, a situation that changes the nature of its value into something of a more aesthetic nature.

Lastly, pornographic games are also based on this kind of economy, where there can be a direct link between points acquired and sexual acts accomplished, or where finishing the game actually means assisting and engaging in all possible sexual acts. As in the previous cases, nudity and sex are here instantaneous and abundant, but with the difference being that there is a crescendo of explicit and obscene representation of sex and nudity.

\footnotetext{
${ }^{12} \mathrm{https}$ ://gamefaqs.gamespot.com/boards/718650-dragon-age-inquisition/70714169 (last visited 17/03/2019).

${ }^{13}$ See Fig. 2.
} 
So there is actually a kind of final reward that is actually both based on reaching the represented orgasm and in having some kind of pornographic-aesthetic gratification, by letting players have access to more detailed, colorful and stimulating pictures or videos.

Love and sex in all these cases are the explicit objects of value for players, the states that absolutely need to be reached from the beginning and until the end.

\subsection{Love, Nudity, and Sex as Gifts and Rewards}

Another interesting possibility consists in having players to face the challenge of a game that is not by itself either about love and sex, and does not include relevant nakedness or sexuality, but that will however reward the player with a love ending, a naked scene, or the representation of a sexual interaction. The first two games that comes to mind here are The Guy Game and Bubble Bath Babes (1991). The first one is a quiz game, whereby correctly answering gains the player access to real footage of women showing their breasts. The second is a "puzzle game" with the same mechanics of games like Puzzle Bobble (1994), but where the final reward for having points and finishing the levels consists in seeing some nakedness. But we could also cite once again $X$-man where the game actually consists in resolving mazes in order to gain access to an 8-bit "interactive pornscene". A mixed and interesting case is also the recent and successful Hunie Pop(2015), that is half-dating simulator and half-puzzle game based on mechanics like Candy Crush.

As in mass-media, many games end with a final kiss or love story that seems to be at least as important as saving the world. So all the efforts and calculations required to finish a game like Final Fantasy 8 (1998), while never directly channeled toward "having a relationship", will lead to a narrative happy ending with a kiss for a previously lonely and unloved character. We will not however indulge on such a point that could constitute a whole book by itself.

Love and sex are in this economy reflect the implicit value of very different type of goals and efforts: like fireworks, on their own they guarantee the meaningfulness of the waiting and struggling to obtain them, the happiness of the ending and the utility of the time spent to get through these texts.

\subsection{Love, Nudity, and Sex as Use and Exchange Value}

At the opposite of what we have just seen, other games actually include love and sex features as something of use to reach other goals. Differing from what we have called the "Economy of Need", when love and sex are 
not the "final objective" nor the reward they are helpful but not necessary.

Sex can give you mental health in a game like Indigo Prophecy where it is the most important resource, relationships can power-up your army in a game like Sakura Wars (2005), having a wife (Stardew Valley) and children (Harvest Moon) both cost you money but are useful for gathering more in-game money and resources, sexually humiliating your opponent on the ring can be used as an alternative way of defeating your challenger as in Rumble Roses, and so on. Here love and sex are part of ideological systems where, for example, the meaningfulness of having a child in Harvest Moon resides in the fact that procreating is another form of "human production" and humans themselves (kids included) are mostly tools of production. The different encyclopedic layers of the text here determine the semantic value of all the lexicalization of love and sex (children, kisses, nakedness, etc..) in conformity with the main isotopies of the texts recognizable exactly through the economic system of the meaning. Thus, love and sex come to mean very different things.

This can also happen in more "innocent ways," as in Enslaved: Odyssey to the West (2010), where the most revealing costume will give the player the unique power to stun the enemy.

Dragon Age" is an interesting case, where having relationships with characters gains the player access to more quests, and consequently more items and experience points (objects useful to win). But we could elaborate by discussing the "aesthetic" benefits of relationships, giving you access to more playtime, beautiful cutscenes, love scenes, etc. There is consequently a meta-level of use and exchange. Outside of simulation, in the concrete game economy you actually do not need to complete these "relationship quests" either to win or to "play more".

All these cases represent very different situations where love and sex values are very closely tied to the possibility of benefits, benefits that actually require in-game previsions and investment, inside of a more complex structure where a certain freedom of not "loving" is virtually present. This of course depends on the concrete numeric situation of a game that could only feint this freedom and actually require love and sex to absolutely win, transforming the convenience of love and sex into something compulsory.

\subsection{Love, Nudity, and Sex as Gratuitous Acts}

In this last case, love and sex are primarily choices of a particular player, without particular in-game benefits.

This is the case of the Photo Mode of DoA Extreme 3 or of the "underskirt" screenshot feature inside Gal Gun VR (2017). On one hand, the sys- 
tem creates the conditions of possibility for such a "free" investment: these sexualized bodies created only to be looked at, "exciting" embarrassment situations and reactions, the possibility of obscene zooms, and much more are all meant for the player to act in some way. Nonetheless, all this is outside of any in-game value in terms of winning or losing, performance and ending, etc. Not only is the player not rewarded for such actions, it is not the ending of a story, and it is not a way to accomplish other goals; he also cannot numerically benefit from this in any way.

The answer to the big "why?" of all of this is a biological, psychological, and even more importantly, sociological one with "trophies" and "achievements" awarded to the players' real accounts (as in Gal Gun VR). Indeed, using the camera to look under a skirt (Lollipop Chainsaw, 2012), or at breasts during a conversation (Asura's Wrath, 2012), are all "free" and not suggested by the game acts; however, they're often anticipated by the game and "grant" an achievement on the social gamers' cards ${ }^{14}$. In a more subtle way, in a game like Metal Gear Solid 2 a camera will be given to the player/character for completing their mission by taking pictures of a very dangerous secret nuclear weapon. However, players will "randomly" find some picture of Asian women in swimsuits in "hidden" places like closets. If players stare at these pictures or use the camera on them, this behavior triggers a "shameful" mini-cutscene where this behavior is derided ${ }^{15}$.

Another example, applied this time to love, is the game InstLife (20172018), where having or not having a love relationship happens without any difficulty and is the choice of a player inside of a game without winning or losing conditions. The depiction of such a relationship simply depends on the kind of simulated life the player wants to see. Here again, of course, the last screen with the number of people attending your funeral could be considered a way for the game to "push you" toward having a relationship. Still, this game is certainly different from the previous cases and does not assume any value outside of a cultural and socio-semiotic meaning context. In this same context we could also cite the ending of Beyond: Two Souls (2013), wherein you can choose to either live happily by yourself or with someone you love.

Also, we can't resist citing here how costly these "gratuities" can be: all the time spend to unlock an almost naked costume (with no beneficial stats) for the beautiful Sheva (Resident Evil 5) or the monstrous Mileena (Mortal Kombat 9), and the real money spent on the DLC for seeing

\footnotetext{
${ }^{14} \mathrm{https}: / /$ www.youtube.com/watch?v=NHluZqfig2M (last visited 17/03/2019).

${ }^{15} \mathrm{https}: / /$ www.youtube.com/watch?v=jwjSHk1Q3po (last visited 17/03/2019).
} 
the Naruto characters in their swimsuits (Naruto Ninja Storm 4). Lastly, there is also a whole dimension in which digital nudity is "secret" and thus assume its value when it is uncovered: the Ring of Power (1991) topless intro with cheat codes, the Enemy Zero (1996) secret shower scene after finishing the game, the Metal Gear Solid (1998) "Meryl in Panties" scene, and so on, all represent this trend. These portions of the games are not only "optional" but often hidden, or at least hard detect because the player must discover them by themselves, in order to secretly "unveil" an "erotic" digital content. But, again: what is the aim of all of this? Nothing is gained outside of the pleasure of unveiling and witnessing such content, falling here again outside of the "win-lose" conditions and of the numerical structure of the game system. We are thus outside of the narrativity system and schema of meaning, but still inside the cooperative textual mechanics and socio-cultural aspects of in-game meaning-making.

In this last economic case we can thus see how, no matter if through extreme struggle (the costume earned by playing many hours, or the shower scene unveiled by finishing first the entire game), or instantly awarded (loving someone in InstLife), many love and sex dimensions ground their meaningfulness in both their scarcity (the hidden, the secret) and systemic uselessness.

\subsection{Conclusions}

We have seen here how the real lifetime finitude of the player gives meaning to love and sex in digital games, particularly once it is invested in a text that by its system's closeness can ensure a high trust and safe bet inside of different regimes of scarcity and values of love and sex features. This last aspect, as demonstrated, is integrated with the narrative structural system and relies on the reader's encyclopedia as cooperative operations of meaning-making deeply rooted within the outside-text socio-semiotic layers of reality.

\section{A Final Word}

A great effort has previously been made to apply the traditional concepts of semiotics to games (Maietti 2004; Meneghelli 2007; Meneghelli 2011; Meneghelli 2013; D’Armenio 2014), this paper represents part of a new semiotic perspective already in course (Thibault 2017), one that looks for a more specific understanding of meaning-making in games through focusing both on sociosemiotic cultural aspects and on the semiotic processes grounding the cognitive and experiential dimensions of these texts. Indeed, they are of interest for us first of all because they are played, and second of all because their meaning is not grasped through simulable patterns but produced through complex and heterogenic mechanism that require semi- 
oticians to work interdisciplinarily. As demonstrated in this article, for a task such as this the concepts of economic projectuality, digital sensibility through ratio, semantic manipulation, and intersubjective enunciation appear to be the key terms to focus on in further research. This perspective, however, should not be thought of as only useful for the specific semiotics of games, but hopefully as a something that could be applied to any kind of text and that can contribute to the general semiotic theory, especially for taking the experiential dimension of meaning as a discourse into consideration as an object that can and should be deconstructed (Volli 2006).

\section{Figures}

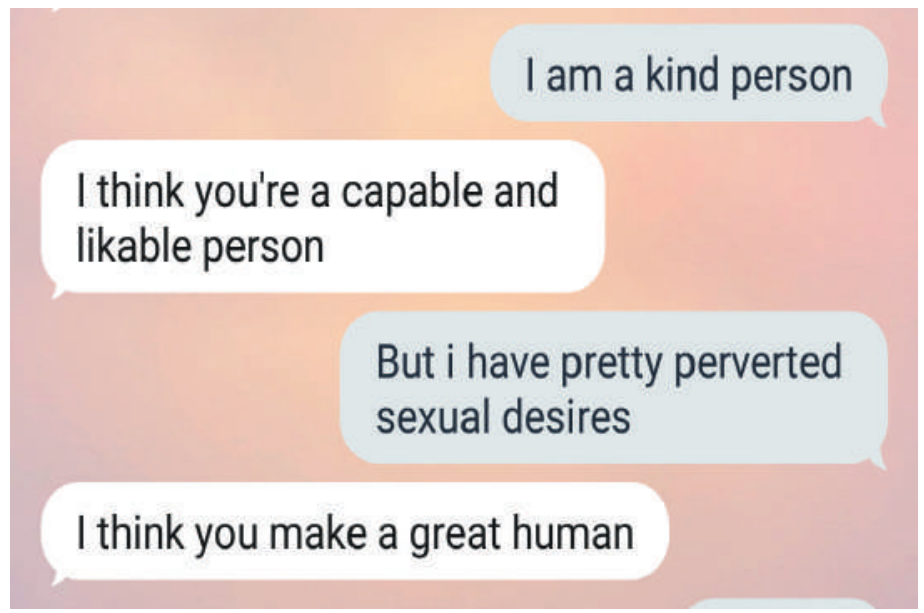

Fig. 1: Replika, 2017

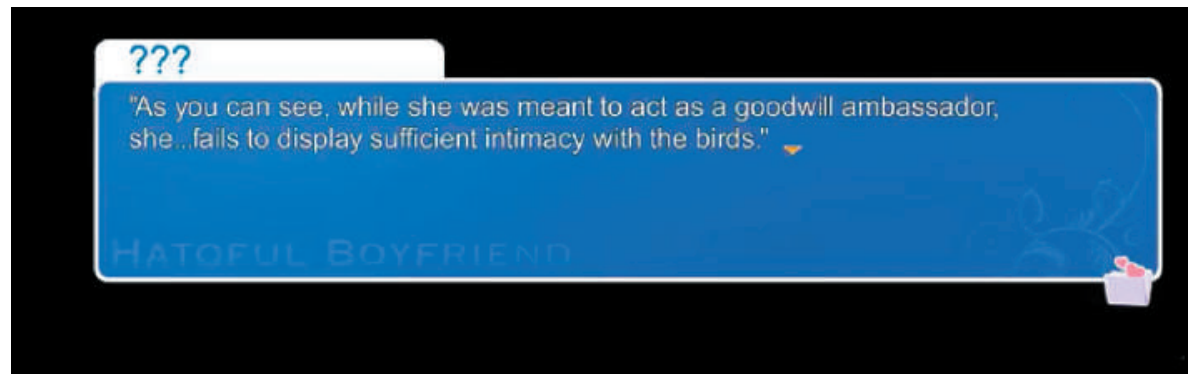

Fig. 2: Game Over screen of Hateful Boyfriend (2011) 


\section{References}

Bankov, K. 2018. Scarcity and Meaning: towards a Semiotics of Economic Transaction. In Cobley, Paul and Alteanu, Alin (eds). Semiotics and its Masters. Vol. 2. Berlin: De Gruyter Mouton, 2018.

Barthes, R. 1977. Fragments d'un discours amoureux. Paris: Seuil.

Bogost, I. 2007. Persuasive Game. Massachusetts: The MIT Press.

Bondì, A. 2010. Il linguaggio come "fenomeno". L'esperienza linguistica fra Saussure e la fenomenologia. RIFL, 3, pp. 39-51.

Bondì, A. 2008. Regimi del senso. La teoria delle 'forme semantiche' tra diversità linguistica e stabilizzazione semiotica. XIV Colloque de la Société Italienne de Philosophie du langage, Siena.

Danaher, J \& McArthur, M. 2017. Robot Sex. Social and ethical implications. MIT, USA.

Degenaar, J. \& O’Regan, K. 2015. Sensorimotor theory and Enactivism. In Topoi (2017) 36: 393.

Eco, U. 2004. Storia della bellezza. Milano: Bompiani.

Eco, U. 1979. Lector in Fabula. Milano: Bompiani.

Ferri, G. 2007. Narrating machines and interactive matrices: a semiotic common ground for game studies. In A. Baba (Ed.), Proceedings of the Digra 2007 Conference, pp. 466-473.

Giuliana, G, T. 2018. Quilting the meaning. Proceedings of Digra 2018.

Grodal, T.K \& Lindegaard,G.A. (2008). Embodiment and interface. In Video Game Theory Reader 2. London: Routledge.

Lakoff, G. \& Johnson, M. 1980. Metaphors We Live By. University of Chicago Press, Chicago, Illinois, Usa.

Marrone, G, Dusi, F and Lo Feudo, G. 2007. Narrazione ed Esperienza: intorno a una semiotica della vita quotidiana, San Giovanni: Meltemi.

Paolucci, C. 2010. Strutturalismo e Interpretazione. Milano: Bompiani.

Picard, R,W. 1997. Affective Computing. Cambridge: MIT Press. 
Pinker, S. 1997. How the Mind Works. NY: Norton.

Sicart, M. 2011. Against procedurality. Game Studies, Volume 11 issue 3 December 2011.

Thibault, M. 2017. The meaning of Play. PhD Dissertation. University of Turin.

Todorov, T. 1982. La conquête de l'Amérique, la question de l'autre. Paris: Seuil.

Volli, U. 2006. È possibile una semiotica dell'esperienza?. In Marrone, G, Dusi, F and Lo Feudo, G. 2007. Narrazione ed Esperienza: intorno a una semiotica della vita quotidiana, San Giovanni: Meltemi. 